\title{
Institutionalising children journalism education in Nigerian communication/media studies
}

\author{
Olusola Oyero
}

\begin{abstract}
The media have a responsibility to voice the rights of children but need to be better equipped to do so. Repositioning the media is best initiated within an educational framework as education brings about progress in practical fields and invariably leads to improvements in society as seen in studies in development communication, health communication, science communication, environmental communication, etc. (Craig, 2000). Children journalism education will undoubtedly go a long way in improving children's media practice. This paper calls for a journalism education programme in Nigeria to remediate the shortcomings observed in the African child's media world and to promote the rights of children and the realisation of their dreams.
\end{abstract}

\section{Key words}

Children journalism education, child rights, institutionalising, Nigeria.

\section{Introduction}

The 1989 the UN Convention on the Rights of the Child assigned certain responsibilities to the media in the pursuit of the fulfilment of child rights. The ultimate aim of these responsibilities is to ensure that materials accessed by children from the media guarantee their social, spiritual, and moral wellbeing, as well as their physical and mental health. Article 17 of the Convention emphasises that key stakeholders in the media industry need to co-operate in all aspects to ensure 
quality production, exchange, and dissemination of information that will be beneficial to children. The media were also encouraged to take the linguistic needs of children (minority group children especially) into consideration in their production and development of appropriate guidelines for their protection from information and material injurious to their well being (UNICEF 2002:6566).

The pronouncement of the world body evolved other discourses such as the Asian Summit on Child Rights and the Media and the Oslo Workshop held in 1996 and 1999 respectively. The relationship between the rights of the child and the media was established in 1996 at the Asian Summit on Child Rights and the Media held in Manila, the Philippines (HURIGHTS, 1996). The media, according to the Summit, should:

- adopt policies that are consistent with the principles of non-discrimination and the best interests of all children

- raise awareness and mobilise all sectors of society to ensure the survival, development, protection, and participation of all children

- address all forms of economic, commercial, and sexual exploitation and abuse of children in the region and ensure that such efforts do not violate their rights, particularly their rights to privacy

- $\quad$ protect children from material which glorifies violence, sex, horror, and conflict; and not perpetuate discrimination and stereotypes

The Summit's resolution further states that media content should be of high quality, made specifically for children, should not exploit them but rather support their mental, social, moral, and spiritual development. When the media enable children to hear, see, and express themselves, their culture, their languages and their life experiences, it will affirm their sense of self and community. In much the same way, the media should be made accessible to children at all times in order for them to benefit from its content. 
Following this, the Norwegian Government and UNICEF responded to a request from the Working Group set up by the UN Committee on the Rights of the Child and convened a workshop in 1999 to coincide with the $10^{\text {th }}$ Anniversary of the UN Convention on the Rights of the Child. Part of the Workshop's resolution -- popularly known as the Oslo Challenge -- was that "the child/media relationship is an entry point into the wide and multifaceted world of children and their rights to education, freedom of expression, play, identity, health, dignity, and self respect, protection; and that in every aspect of child rights, in any element of the life of a child, the relationship between children and the media plays a role" (Onumah, 2004:65; The MediaWise Trust, 2003).

The challenge is a call to action with the aim of ensuring that the overwhelming positive power of the media on children is identified, encouraged, and supported while the potentially harmful effects are recognised and reduced by the media practitioners. The Oslo Challenge also assigns media practitioners the crucial role of acting as a catalyst for the realisation of children's unfulfilled dreams. The media should design appropriate programmes that will empower children to make informed choices and actively participate in society by realising their rights to life, freedom of expression, education, sound health, and protection from abuse, exploitation, and violence.

Consequently, this paper proposes that, in order for the Nigerian media to be effectively equipped to honour these responsibilities, there is a need for journalism education or training entirely devoted to children. Attention has indeed been given to certain sectors of society within the context of Mass Communication: the emergence of development communication, health communication, science journalism, environmental communication, economic journalism, etc, has aided experts in achieving specific objectives for the growth and benefits of society. A similar innovation for children commencing at the level of education is indispensable in raising awareness of children's many unfulfilled dreams. Children journalism education would therefore 
refer to the kind of education that trains individuals as experts to meet the media needs of children. Such education, as envisaged, would go beyond the traditional training of journalists by expanding its curriculum to train individuals as children media professionals who will have the responsibility of placing children in the news, thereby setting the agenda for the fulfilment of their educational, cultural, and social rights. Such education would involve research on children and the media for the purpose of enhancing better practice in this specialised area. In other words, it would be a university programme that teaches news and editorial courses and conduct research in journalism and communication in relation to children's needs.

\section{Theoretical considerations}

The paper draws from the functionalist perspective of education and Everett Rogers' theory of innovation diffusion. The functionalist posits that schools make a number of vital contributions to the survival and perpetuation of modern societies, including the completion and socialisation process and creating new knowledge through research and development (Hughes \& Kroechler, 2008). According to functionalists, the knowledge and skills required by contemporary living cannot be satisfied in a more or less automatic and natural way as it was in many pre-literate and peasant societies; instead, "a specialized educational agency is needed to young people in the ways of thinking, feeling, and acting mandated by a rapidly changing urban and technologically based society" (Hughes \& Kroechler, 2008: 372). Schools, particularly universities, do not only transmit culture, they also add to the cultural heritage. Emphasis is now placed on the development of new knowledge especially in sciences, medicine, and engineering thus rendering universities research centres. University professors are no longer assessed according to their teaching activities alone but also by how much they are involved in research. Functionalism sees the university combining the functions of research and education which allows the students to benefit from the intellectual stimulation of research orientation prevalent within the university.

Education may be formal or informal but the emphasis here is on a formal education. The Online Free Dictionary defines formal education as a conscious effort by human society to impart the skills and modes of thought considered essential for social functioning. It involves training and 
developing knowledge, skills, mind, and character through a structured and certified programme. Education is believed to be responsible for the cultivation of a civilized society. Imparting knowledge and skills to the citizens helps society as a whole in its development of a responsible and thoughtful entity. Education brings about progress in practical fields to enable each educated individual in society to earn a living and to better conditions of co-existance as a whole; this is because education aims at making the individuals of society self-sufficient. Education in the various practical fields therefore produces productive human resources, which can contribute to the creation of wealth for a country. While people earn money for their work, they are also creating something to financially benefit their organisation. Every organisation is a part of the nation and thus shares the nation's responsibility for achieving monetary gains (Oak, n. d.).

Innovation can be applied with the aim of increasing the adoption of children journalism education as part of media/communication education curricula in Nigeria. This theoretical framework underpins the idea of children journalism education as an innovation in journalism education studies. While innovations can be of divergent dimensions, the nature and manner in which people adopt a particular innovation follows a similar format and trend. Fourie (2001) notes that the media themselves can be considered an innovation and also assist with the creation of awareness on innovation.

The main elements in the diffusion of new ideas are: (1) an innovation; (2) which is communicated through certain channels; (3) over time; (4) among the members of a social system. An innovation is an idea, practice, or object perceived as new by an individual or other unit of adoption. The characteristics of an innovation, as perceived by the members of a social system, determine its rate of adoption. Five attributes of innovations are: (1) relative advantage: the degree to which the innovation is perceived to be superior to current practice; (2) compatibility: the degree to which the innovation is perceived to be consistent with sociocultural values, previous ideas, and/or perceived needs; (3) complexity: the degree to which an innovation is difficult to use or understand; (4) trialability: the degree to which the innovation 
can be experienced on a limited basis; (5) observability: the degree to which the results of an innovation are visible to potential adopters.

Time is involved in diffusion at three levels:

- the innovation-decision process is the mental process through which an individual (or other decision-making unit) passes from first knowledge of an innovation to forming an attitude toward the innovation, to a decision to adopt or reject, to implementation of the new idea, and to confirmation of this decision. This process consists of five stages: knowledge, persuasion, decision, implementation, and confirmation

- innovativeness is the degree to which an individual or other unit of adoption is earlier in adopting new ideas than other members of a social system. Innovativeness determines the type of adopter categories, namely: innovators, early adopters, early majority, late majority, and laggards

- the innovation rate of adoption is the relative speed at which an innovation is adopted by members of a social system

A social system is a set of inter-related units that are engaged in joint problem-solving to accomplish a common goal. A system has structure, defined as the patterned arrangements of the units in a system, which gives stability and regularity to individual behaviour in a system. Social systems can be characterised as heterophilous or homophilous. On the one hand, heterophilous social systems tend to encourage change from system norms. In them, there is more interaction between people from different backgrounds, indicating a greater interest in being exposed to new ideas. These systems have opinion leadership that is more innovative because these systems are desirous of innovation. On the other hand, homophilous social systems tend toward system norms (Wejnert 2002). Most interaction within them is between people from similar backgrounds. People and ideas that differ from the norm are seen as strange and undesirable. These systems have opinion leadership that is not very innovative because these systems are averse to innovation. 
The media faces constant social challenges and expectations to respond appropriately to the rights of children. There is therefore a need to reconfigure journalism practice from an educational standpoint in order for it to fulfil this social requirement. Thus, children journalism education is a necessary innovation in a country like Nigeria where children are in critical situations with little or no help from the media.

\section{Social relevance of journalism education}

The social relevance of journalism education is underscored by the importance of journalism practice in society. The media occupy a strategic position in influencing the course of events in society (Rahaman, n.d.) because they are custodians of and accessories to information. Essentially, whatever journalists decide to do with the information available to them determines the direction in which society moves. This has been a major theoretical assumption in the agenda setting role of mass media. As Cohen (1963:13) observes, the mass media determines the issues that are to be regarded as important at a given time in a given society. This means that the press is significantly more than a purveyor of information and opinion and although it may not be able to tell its readers what it thinks, it is successful in telling them what to think about. In other words, our perception of the world is dependent not only on our personal interests but also on the map that is drawn for us by media practitioners.

Furthermore, the media represent the conscience of the public. They serve as a watchdog over the activities of government and incontrovertibly mould the opinion of the public as well as act as an essential agent in facilitating the development of any society. As Lasswell notes, journalism has three functions: news function, the interpretative function, and the opinion function (Severin \& Tankard, 1992: 293). The corollary functions of education and entertainment are performed by the press as part of their social responsibilities. In other words, these functions boil down to information, enlightenment, and persuasion. 
The mass media have the responsibility to educate the citizens on national politics, geography, history, people, and cultures. Journalists are therefore undoubtedly relevant in the process of nation-building. Basically, the press/mass media play important roles that may be described as social, motivational, entertaining, educational, advertising, and informative. The socialisation function consists of inculcating societal norms and values in citizens to make them behave in particularly desirable ways in the general efforts to achieve national objectives. The media also educate people about the past, present, and future as well as entertaining (through the use of cartoons, for example). It can thus be conveniently observed that the media and its practitioners are relevant in society because of their roles in educating, informing, entertaining, and enlightening the public on social, economic, political, cultural, and educational issues. These roles have sustained the quest for training in the profession and the success of its practice.

\section{The imperatives of children journalism education in Nigeria}

Current journalism education in Nigeria does not cater to the needs of children. One of the reasons for this is that Nigerian journalism practice, like many English-speaking African countries, has been influenced by the American approach (De Beer, 2010). The United States assisted with journalism training in Nigeria (such as the effort of the then United States Information services (USIS), now known as the Public Affairs Department of the United States Embassy, which sponsored journalism travelling workshops in Nigeria). In addition to this most of the early Nigerian communication scholars were trained in the United States (Oduko 1992; Salawu 2007). The consequence of this is gross neglect of Nigerian peculiarities in journalism curriculum formulation, training, and its output in practice.

Mensing (2010) notes that journalism education has hitherto focused on the reporter and the basic functions of information gathering, evaluation, production, and distribution and while convergence and multimedia have added some significant changes, "the essential flow of journalism education has changed little in response to the epochal transformation taking place within communications" (p.512). It is on this wise note that Mensing (2010) advocated 
reconfiguration of journalism education because journalism education's goal should be about building functioning communication structures. The traditional pattern of journalism education and its practice has thus failed to connect with the realities of the development needs of vulnerable members of society like children. Unfortunately, most children in Nigeria are in critical situations. Many are forced to engage in child labour and are denied access to education and good health care. Many others suffer from human trafficking and economic, physical, and sexual exploitation. The UNICEF's (2011) report on State of the World's Children shows that no fewer than 794,000 children die annually in Nigeria before they turn five and that out of 1000 children born in 2009, 86 Nigerian children died before they were one-year-old. Anyone born in Nigeria is not expected to live beyond 48 years of age. In addition, about 360 children out of 1000 live with HIV and as of 2009, about 2.5 million children have already been orphaned by AIDS. This situation calls for a responsive journalism that will work and cater for the best interests of children -- thus the need for an educational framework to provide such journalism practice.

In Nigeria, the absence of a specialised journalism education has created a vacuum in the world of child media. The derth of well-trained journalists equipped to report on issues affecting children is reflected in the poor attention given to children in media coverage . Oyero's (2011) study on the coverage of children's issues in Nigerian national newspapers shows a gross underreportage of children. In a study that examined five years of newspaper content, reports on children accounted for less than one percent of the total stories reported. In another study on three categories of Nigerian newspapers (state, regional, and national newspapers) by Ajibola (2010), children's issues received lukewarm reception as compared to other news and only 0.6 percent of the total stories were on children. This may well be because there are few or no experts to report on children's issues.

Although one can contest that the poor coverage given to children is due to the social construction of children by the media as unimportant entities in societal decision-making processes, immature, ill-informed or, indeed, as not interested in current affairs (McNamara, n. 
d.), the Nigerian media have the social responsibility to bring children's issues to the fore -particularly in view of the precarious situation of children and the implications this situation has for development and the future. It is thus obligatory for the media to give deliberate attention to children in news coverage, no matter how unimportant or unworthy children may be for news production. It is believed that children journalism education will not only foster interest in reporting about children but also enhance the desired deliberate coverage that children deserve in the media.

This lacuna is also evident in the scarcity of research in the area of children and media in Nigeria. Osei-Hwere \& Pewra (2008) pointed out that little is known about the experience of African children either as media audience or creators. This is because little or no research on children is being carried out in respect of the media and children in Africa. It has been observed that in 20 years of analysing the research done on children and television, there has never been a discussion on African children published in US academic journals (Pecora, Murray \& Wartella, 2007). Not only that, but a "global study" by MTV which involved 16 countries had no research on the African continent (Biz-Community, 2007). While some efforts are in progress in Ghana and South Africa, there is no knowledge of such efforts in Nigeria. As it is mostly academics in higher institutions who conduct research in Nigeria, it is logical that a paucity of research on children and the media will exist, especially in view of the fact that there are no institutions working in this field.

The importance of research in realising children's rights cannot be under-estimated. Some sections of the UN Convention on the Rights of the Child have been criticised as vague, thus demanding re-examination and re-presentation. Some of the duties assigned to the media in Article 17 of the UNCRC need to be researched in order to assess their viability. For example, Sections B and E of Article 17 require the State Parties to encourage "international co-operation in the production, exchange and dissemination of such information and material from a diversity of cultural, national and international sources" and "the development of appropriate guidelines for the protection of the child from information and material injurious to his or her well being". 
It is necessary to spell out the specific ways in which these objectives will be achieved by the media. Research will no doubt be beneficial in this regard. Unfortunately, while child rights organisations have stressed the importance of the media to the realisation of children's rights, they have not seen the need to promote children journalism education as a core area in media training. UNESCO has proposed a model curriculum for journalism training, with special courses in economic journalism, science and technology journalism, sports journalism, political journalism, but nothing on children. Although UNICEF has been trying to emphasise the need for children's issues to be included in communication training programmes through its Workshop on the ACADA model of development communication for media professionals and educators (held in Nigeria on several occasions), it has remained on the periphery and has had no impact in changing media education programmes in favour of children.

A number of conferences, workshops, and meetings have been held to uphold the rights of the child, but these have to a large extent excluded journalism and media trainers and as such have not called on the contribution of media educators in advancing the rights of the child. The Oslo Challenge of 1999 is a glaring example. The Oslo challenge sought the active contribution of governments, organisations and individuals working for children, media professionals, private sectors and media owners, parents, teachers, researchers, and children themselves in fulfilling the rights of children. However, an important sector was neglected and that was the media educators. While media practitioners and producers are included in the call, those who train these media professionals are excluded.

An issue which may be of concern for children journalism education is the market value of such education. Would media producers find it profitable gathering and disseminating news for and about children considering the cost of production and payment of staff? As children journalism reports children's issues to the general society and is not directed at children alone, the market value is guaranteed. While media content aimed at children may not carry as much weight as other societal news, the pattern of presentation will also determine its reception by the public in general and children in particular. An example is the BBC Newsround for children which has 
been structured to meet children's media needs. In addition, children have a way of influencing their parents or guardians about products, including media content. So, when news content is judiciously presented to be attractive to children, it will receive necessary patronage and subscription.

\section{Aims and core courses for children journalism education in Nigeria}

It is necessary to note that these aims and core courses stem from the understanding that this writer has about the essence of children journalism education in relation to Nigeria's milieu, as well as thoughts shared by colleagues on the subject. While they have not been used anywhere before, it is believed that these aims will serve as a springboard to initiate an ongoing project in the suggested direction.

Children journalism education is designed, among other things, to:

- provide students with a balanced and broad-based training in children journalism media

- provide sound, theoretical, and practice-based education in children journalism/mediacentred domains of mass communication

- equip students with knowledge of children journalism practice in Nigeria and the world through the study of concepts, theories, and methods that provide such knowledge

- expose students to modern developments and technology in information gathering and dissemination for and of children through the mass media, with emphasis on computerassisted reporting, online journalism, and multimedia production

- evolve appropriate philosophies and policies for the operation and management of Nigeria's communication industry for the benefit of children

- engineer efficient and effective communication support services for various human and national development programmes towards the realisation of the rights of the child

- undertake research on a continuous basis into the state of the African and Nigerian child and communication media and make the findings available to policy makers 
Children media education should cover areas such as print and broadcast media, as well as online and multimedia production. Here we prescribe such courses, among others, that this specialised field should cover:

\section{Theories of children media}

This course will deal with the theoretical foundation of media for children. It draws relevant theories from different disciplines that explain the social-cultural construction of children and how they intersect with issues of gender, resources, citizenship, education, etc.

\section{Children media research}

This course will provide an overview of qualitative and quantitative research methods used in the investigation of topics related to the studying of children media. Methods covered may include, inter alia, textual analysis, survey and content analysis, ethnographic methods, and qualitative approaches to historical research. The course would examine the important steps, tools, and techniques used in these methods. Particular attention should be paid to the application of these methods in doing research on children and the media, including impact assessment of media content on children and determining the suitability of programmes for children.

\section{Law and ethics of children media}

Within the broad scope of journalism ethics lies the specific ethical consideration for reporting about children and media production for children. It discusses ethical and moral standards for the mass media in the coverage of children and the ethical responsibilities of individuals, groups, and media organisations toward children. It will examine how mass communication law works in the country with an emphasis on the Convention on the Rights of the Child and its domestication in the form of the Child Rights Act.

\section{Communication for children's development}


This course deals with the role of mass communication media, multimedia, indigenous, and other communication channels in the overall development of children. It targets various methods of appropriate communication for stakeholders in respect of the fulfillment of children's rights.

\section{News writing and reporting}

The course will focus on news reporting and writing techniques used in both traditional print media, Internet publishing, and broadcast media. Students will be introduced to the basics of accuracy, clarity, word choice, journalistic style, story structure, and deadlines. It will highlight style and structure of news stories, news sources, newsroom practices and procedures and will include reporting assignments for publication and broadcast on children's issues.

\section{Children, media, and society}

This course introduces students to mass communication theory as it relates to practical applications in today's society. To assist in the use of mass media, students need to equip themselves with a better understanding of how theories can explain the role of the media in the lives of children as individuals and as members of a social group. This knowledge is important in helping to guide and critique today's changing media industries as they affect children in contemporary Africa.

\section{Child audiences}

The course examines the way children of different categories experience media news and entertainment in the context of social influences and expectations. It examines children's attitudes and behaviours to different media and the influence of new media on children's consumption of media content.

\section{Economics of children media}

This course deals with the business and financing of children media in a developing world. It deals with the issue of costs and benefits that accompany the production of children media 
content, as well as the plan, production, and delivery of this content. Emphasis is given to the economic gains of running a course of this nature.

These courses are by no means exhaustive. The development of a special area of this nature is a continuous one. But the courses outlined above will serve as a framework for the development of a well-grounded programme. For example, there is no inclusion of computer games, online journalism, and multimedia production, all of which have become part of the African child experience. All of these will need to be built into a viable children media education programme in Nigeria.

\section{Conclusion}

The adoption of the courses outlined above will ensure that the peculiar needs and desires of the children of Nigeria and Africa are catered for, even as required by the African Charter on Children's Television and the Oslo Challenge among others. For instance, the African Charter on Children's Broadcasting held that children have quality, well funded programming addressing the developmental needs of children. In addition, it subscribes that children should be protected from commercial exploitation, be ensured equitable access to programmes and, where possible, be involved in the production process, their programmes must empower children, and there should be ongoing research into the child audience, including the child's needs and wants. The foregoing will only be achieved when the prescribed courses among others are taught in journalism and media schools in Nigeria.

It is therefore necessary for journalism and communication institutions in Nigeria to begin to incorporate children media education as part of their curricula. The ideal is to incorporate it as one of the specialisations at either the undergraduate or the graduate level. Institutions can also introduce short-term certificate or diploma courses in this direction. Although there has been inadequate response from media educators and practitioners contacted to share opinion on this topic, the little feedback received has been positive. 
Professor Norma Pecora of the School of Media Arts and Studies, Scripps College of Communication, Ohio University, sees the idea as worthwhile in helping media practitioners understand the particular needs of the child (Pecora, e-mail personal communication, 19 May 2011) -- an idea further supported by Jide Ajani, an editor of one of Nigeria's national newspapers, Vanguard (Ajani. Personal Communication, 15 July 2011). Similarly, Professor Chris Goddard, director of Child Abuse Prevention Research Australia, Monash University, supported the idea of specialised journalism education for the benefit of children. He particularly noted that his centre's studies have shown how the language used by journalists is both disrespectful to children and minimises the seriousness of child abuse. Furthermore, journalists use language that reduces the emotional impact of abuse and even call a child "it" when his or her gender is known. He thus described the idea for a "specialism in writing FOR children" as excellent (Goddard, e-mail personal communication, 6 September 2011).

At present there is no single communication or media training school in Nigeria that teaches children journalism education and it is most likely that the same applies to many media training institutions in the rest of Africa. We can, however, refer to centres that do something similar to what is being proposed here: such as the Journalism Center for Children and Families at the University of Maryland, United States.

With the adoption of children media education, we can be sure of better living conditions for the Nigerian child as the media will be better positioned to meet the needs of children and guarantee the recognition of their rights in accordance with the UN Convention on the Rights of the Child and other documents. 


\author{
About the author \\ Olusola Oyero lectures in the Department of Mass Communication at the College of \\ Development Studies at Covenant University, Ota, Nigeria. \\ Contact details: oyero.sola@gmail.com. +234-39250556
}

\title{
References
}

Ajibola, A. (2010). Coverage of child rights in selected Nigerian newspapers: A study of the Guardian, Tribune and Gateway Mirror (Unpublished B. A. Project). Covenant University, Ota, Nigeria.

Biz-Community (2007). South Africa: Study highlights youth tech use across cultures. Africa News, 2 August 2007.

Cohen, B.C. (1963). The press and foreign policy. Princeton NJ: Princeton University Press.

Craig, R. T. (2000). Communication. Encyclopedia of Rhetoric. Oxford: Oxford University Press. Retrieved 9 June 2001 from the World Wide Web: http://spot.colorado.edu/ craigr/Communication.htm

De Beer, A. S. (2010). Looking for journalism education scholarship in some unusual places: The case of Africa. Communicatio. 2: 213-226.

Fourie. P. J. (Ed). (2001). Media Studies: Institutions, theories and issues. Volume 1. Landsdowne: JUTA.

Hughes, M. \& Kroechler, C. J. (2008). Sociology: The core ( $8^{\text {th }}$ ed.). New York: McGraw Hill. HURIGHTS (1996). Asian Summit on child rights and the media. Retrieved 12 April 2006 from the World Wide Web: http://www.hurights.or.jp/asiapacific/no_05/06asiansummit.htm

McNamara (n. d.). Silent victims and pretty props: The representation of young people in Irish national newspapers. Retrieved 11 June 2011 from the World Wide Web;

www.nordicom.gu.se/cl/publ/electronic/PaulMcIreland1.pdf.

Mensing, D. (2010). Rethinking (again) the future of journalism education. Journalism Studies, 11 (4): 511-523.

Oak, M. (n. d.). Buzzle.com. Education. Intelligent Life on the Web. Retrieved 30 May 2011 from the World Wide Web; http://www.buzzle.com/articles/beliefs-about-the-purpose-of- 


\section{education.htm}

Oduko, S. (1992). Guide to Students Research: A bibliography of mass communication. Lagos: VDG Press Ltd.

Onumah D. (2004). Media literacy and the Nigerian child. The Guardian, 22 November 2004: 65.

Osei-Hwere, E. \& Pecora, N. (2008). Children media in Sub-Saharan Africa. In N. Pecora, E. Osei-Hwere \& U. Carlson (Eds), African Media, African Children. Sweden: The International Clearinghouse on Children, Youth and Media/ NORDICOM University of Gothenburg.

Oyero, O. S. (2011). How children are reported in Nigerian newspapers: Implications for the right of the child. International Journal of Social and Management Sciences, 4(1): 37-56.

Pecora, N., Murray, J. P. \& Wartella, E. (2007). Children and television: Fifty years of research. Mahwah, NJ: Lawrence Erlbaum Associates, Publishers.

Pecora, N. O. (1997). The business of children's entertainment. New York: The Guilford Press.

Rahaman, O. (n.d.). Relevance of journalism in human society. Retrieved 12 June 2011 from the World Wide Web: http://searchwarp.com/swa390939.htm

Salawu, A. (2007). The growth and development of African media studies. Perspectives from Nigeria. Journal of African Media Studies, 1 (1): 52-61.

Severin, W. J. \& Tankard, J. W. (1992). Communication theories: Origins, methods, and uses in the mass media. New York: Longman

The MediaWise Trust (2003). The Oslo challenge. Retrieved 8 May 2007 from the World Wide Web: http://www.mediawise.org.uk/display_page.php?id=130

Todd, J. (n. d.). Functional and conflict theory: A point of view. Retrieved 30 May 2011 from the World Wide Web:

http://www.helium.com/items/779460-functional-and-conflict-theory-a-point-of-view?page=4

UNICEF (2011). State of the world children. New York: Unicef.

UNICEF (2002). A world fit for children. New York: Unicef.

Wejnert, B. (2002). Integrating models of diffusion of innovations: A conceptual framework. Annual Review of Sociology, 28: 297-326. 